\title{
Assessment of effective face mask ventilation is compromised during synchronised chest compressions
}

\author{
Trang Huynh, ${ }^{1}$ Rae Jean Hemway, ${ }^{2}$ Jeffrey M Perlman ${ }^{1}$
}

${ }^{1}$ Division of Newborn Medicine, Department of Pediatrics, New York Presbyterian Hospital, New York, USA

${ }^{2}$ Division of Nursing, New York Presbyterian Hospital, Weill Cornell Medical College, New York, USA

\section{Correspondence to} Professor Jeffrey M Perlman, Department of Pediatrics, New York Presbyterian Hospital, Weill Cornell Medical College, 525 East 68th Street, Suite N-506, New York, NY 10065, USA; jmp2007@med.cornell.edu

Received 28 February 2014 Revised 11 August 2014 Accepted 26 August 2014 Published Online First 19 September 2014

\section{CrossMark}

\footnotetext{
To cite: Huynh T, Hemway RJ, Perlman JM. Arch Dis Child Fetal Neonatal Ed 2015;100: F39-F42.
}

\begin{abstract}
Background Delivery room cardiopulmonary resuscitation is rare. Recent evidence suggests that effective ventilation may be compromised during chest compressions (CC).

Objectives To determine whether trained neonatal personnel can assess effective ventilation during $\mathrm{CC}$ in the setting of changing lung compliance.

Methods Neonatal providers $(n=30)$ provided CC using a 3:1 CC to ventilation ratio performed for 2 min, with lung compliance adjusted every $30 \mathrm{~s}$ from 0.5 (low) to $1.0 \mathrm{~mL} / \mathrm{cmH}_{2} \mathrm{O}$ (normal), followed by face mask ventilation

\section{What is already known on this topic}

Administration of cardiopulmonary resuscitation in the delivery room is uncommon.

- Prior focus has been on improving the ergonomics of chest compressions.

- Recent data suggest that there is substantial mask leak during chest compressions as well as compromised tidal volume with higher chest compression to ventilation ratios.
\end{abstract} (FMV) alone for $1 \mathrm{~min}$. A neonatal lung simulator connected to a neonatal manikin was used to simulate the volume/pressure relation at low and normal compliance.

Results Group analysis showed no difference in peak inflating pressure (PIP) at low versus normal compliance, but a threefold increase in tidal volume (TV) $(p=0.00005)$ during synchronised CC. Paired analysis demonstrated minimal change in PIP, but a significant decrease in TV at low versus normal compliance. During FMV only, a significant decrease in PIP and increase in TV was noted with improved compliance. The face mask was incorrectly applied in $12(40 \%)$ cases and in 20/30 (67\%) providers did not perceive a change in compliance. During FMV only, $7 / 30(23 \%)$ took corrective steps to achieve chest rise.

Discussion Most providers cannot assess the effectiveness of delivered TV in the face of changing compliance during synchronised CC, limiting the ability to make appropriate and necessary adjustments. This may prolong cardiopulmonary resuscitation and result in escalating therapies unrelated to the delivery of effective ventilation.

\section{INTRODUCTION}

Administration of cardiopulmonary resuscitation (CPR) in the delivery room is uncommon and estimated to occur in about one in 1000 newborn infants. ${ }^{1} 2$ The mechanisms leading to profound bradycardia (heart rate $<60 \mathrm{bpm}$ ) or asystole at birth, are invariably a consequence of an asphyxial process secondary to interruption of placental blood flow. Consequently, effective ventilation is the most important intervention necessary to achieve recovery of spontaneous circulation during delivery room resuscitation. ${ }^{3}$ Much of the focus in the past has been directed towards optimising effective chest compressions (CC). Thus, it has been previously shown in manikin models, that use of the two thumb technique and a 3:1 CC to ventilation ratio enhances the ergonomics of $\mathrm{CC}^{4-7}$ More recently there has been a focus on provider ability to deliver effective ventilation during CC.

\section{What this study adds}

The majority of providers cannot perceive whether delivery of tidal volume is effective in the face of changing compliance during chest compressions.

- When compliance improves, providers fail to lower the inflating pressure resulting in a tripling of tidal volume delivered.

- With face mask ventilation only, some providers took corrective action to achieve chest wall excursion at low compliance, and most lowered inflation pressure with normal compliance.

Schmölzer et al used a neonatal manikin and reported substantial mask leak during CC. ${ }^{8}$ In a second study, Solevag et al noted compromised tidal volume (TV) with higher CC to ventilation ratios when compared with a $3: 1$ ratio. ${ }^{9}$ Upper airway obstruction and low compliance (LC) are additional factors that may compromise the ability to deliver effective $\mathrm{TV}^{10}$ Given these potential complicating factors, the provider is often guided by a prompt increase in heart rate and/or chest wall excursion as the best clinical indicators of effective ventilation. ${ }^{11}$ During coordinated face mask ventilation (FMV) and CC, the effectiveness of ventilation is more difficult to assess. The availability of a newborn lung simulator consisting of a newborn manikin and an external lung, with the ability to simulate the volume/pressure relation of newborn lungs right after birth (LC) through transition to aerated lungs with normal compliance (NC), provides an opportunity to assess this complex relationship. The study objective was to determine whether trained neonatal personnel can assess effective ventilation during $\mathrm{CC}$ in the setting of 
Table 1 Group analysis of peak inflating pressure (PIP) and tidal volume in subjects at low and normal compliance during the first and second $60 \mathrm{~s}$ of combined chest compressions and FMV, and during FMV only

\begin{tabular}{|c|c|c|c|c|}
\hline & First minute & Second minute & & \\
\hline CC/FMV & $\begin{array}{l}\text { PIP }\left(\mathrm{cm} \mathrm{H}_{2} \mathrm{O}\right) \\
30 \mathrm{~s}\end{array}$ & $\begin{array}{l}\text { TV }\left(\mathrm{mL} / \mathrm{cm} \mathrm{H}_{2} \mathrm{O}\right) \\
30 \mathrm{~s}\end{array}$ & $\begin{array}{l}\mathrm{PIP}\left(\mathrm{cm} \mathrm{H}_{2} \mathrm{O}\right) \\
30 \mathrm{~s}\end{array}$ & $\begin{array}{l}\text { TV }\left(\mathrm{mL} / \mathrm{cm} \mathrm{H}_{2} \mathrm{O}\right) \\
30 \mathrm{~s}\end{array}$ \\
\hline Low compliance & $\begin{array}{l}37.5 \pm 6.2 \\
\text { (median } 40 \text { ) } \\
\text { range 18-45 }\end{array}$ & $\begin{array}{l}3.8 \pm 1.76 \\
\text { (median 3) } \\
\text { range } 2-10\end{array}$ & $\begin{array}{l}38 \pm 4.7 \\
\text { (median } 40 \text { ) } \\
\text { range 18-45 }\end{array}$ & $\begin{array}{l}4.0 \pm 2.1 \\
\text { (median 3) } \\
\text { range } 2-10\end{array}$ \\
\hline Normal compliance & $\begin{array}{l}36.2 \pm 6.6 \\
\text { (median } 38 \text { ) } \\
\text { range 18-45 }\end{array}$ & $\begin{array}{l}13.8 \pm 6.2^{*} \\
\text { (median 15) } \\
\text { range } 3-30\end{array}$ & $\begin{array}{l}35.4 \pm 6.9 \\
\text { (median 38) } \\
\text { range } 20-45\end{array}$ & $\begin{array}{l}13.1 \pm 5.0 * \\
\text { (median } 15 \text { ) } \\
\text { range } 4-20\end{array}$ \\
\hline \multicolumn{5}{|l|}{ FMV only } \\
\hline Low compliance & $\begin{array}{l}40.5 \pm 5 \\
\text { (median 38) } \\
\text { range 18-45 }\end{array}$ & $\begin{array}{l}3.7 \pm 1.27 \\
\text { (median 3) } \\
\text { range 2-8 }\end{array}$ & & \\
\hline Normal compliance & $\begin{array}{l}33.4 \pm 8.5^{*} \\
\text { (median 35) } \\
\text { range 20-45 }\end{array}$ & $\begin{array}{l}16.2 \pm 3.56^{*} \\
\text { (median } 16 \text { ) } \\
\text { range } 6-22\end{array}$ & & \\
\hline
\end{tabular}

changing lung compliance. We hypothesised that effective ventilation will be difficult to assess during coordinated FMV and CC with changing lung compliance.

\section{METHODS}

This was an Institutional Review Board approved study and consent was obtained from each subject. Subjects included neonatal nurses $(n=18)$, neonatal fellows $(n=5)$, nurse practitioners $(n=2)$, paediatric residents $(n=3)$ and neonatal attendings $(\mathrm{n}=2)$. The protocol included CC using a 3:1 CC to ventilation ratio, and a two-thumb encircling hands technique coupled with FMV using a Laerdal self-inflating bag (Laerdal Corporation, Norway) which was performed for $2 \mathrm{~min}$, with lung compliance adjusted every $30 \mathrm{~s}$ from $0.5 \mathrm{~mL} / \mathrm{cm} \mathrm{H}_{2} \mathrm{O}$ (LC) to $1.0 \mathrm{~mL} / \mathrm{cm}$ $\mathrm{H}_{2} \mathrm{O}$ (NC). Subjects then performed FMV alone for $1 \mathrm{~min}$ which included $30 \mathrm{~s}$ at LC and $30 \mathrm{~s}$ at NC. Subjects were randomised to begin FMV at either LC or NC.

A Laerdal neonatal lung simulator connected to a modified Neonatal Laerdal manikin (Laerdal Corporation, Norway) was used to simulate the volume/pressure relation of newborn lungs right after birth (LC) and the transition to aerated lungs with NC. The upper airways of the manikin are directly connected to the Newborn Lung Simulator lung which is made of glass. There are no valves to direct the air flow, hence leak is minimised to the amount that could leak from face-mask coupling. Volume of air is measured internally, and is proportional to the distance travelled by the carbon piston within the glass cylinder.

The manikin approximates a $6 \mathrm{~kg}$ infant. The ventilation pressures and volumes were continuously recorded and downloaded to a computer for subsequent analysis. Compliance was adjusted while peak inflating pressure (PIP) $\left(\mathrm{cmH}_{2} \mathrm{O}\right)$ and inspiratory TV wave forms $(\mathrm{mL})$ were measured. At LC there is minimal chest movement, whereas at NC the chest wall movement is readily apparent. Subjects did not receive feedback on their performance during the study period.

\section{Methods to improve ventilation with changing compliance during FMV}

As part of neonatal resuscitation programme training, providers are instructed to use the acronym MR SOPA-M: mask adjustment R: reposition airway $S$ : suction mouth and nose $\mathrm{O}$ : open mouth $\mathrm{P}$ : pressure increase A: airway alternative, if there is no response in heart rate or a lack of chest rise during resuscitation. During the study, subjects were observed for proper mask application and positioning of the neck as well as the use of MR SOPA at any stage.

\section{Data analysis}

The sample size was one of convenience. Data were analysed using $t$ tests (unpaired and paired). Wilcoxon matched pairs analysis was used to test non-normally distributed data. All data are presented as a mean \pm SD.

\section{RESULTS}

\section{FMV/CC (group analysis)}

During the initial $60 \mathrm{~s}$, the PIP at LC versus NC was $37.5 \pm 6.2$ versus $36.2 \pm 6.6 \mathrm{~cm} \mathrm{H}_{2} \mathrm{O}(\mathrm{p}=0.22)$. The $\mathrm{TV}$ generated at $\mathrm{LC}$ versus $\mathrm{NC}$ was $3.8 \pm 1.76$ versus $13.8 \pm 6.2 \mathrm{~mL} / \mathrm{cm} \mathrm{H}_{2} \mathrm{O}$ $(\mathrm{p}=0.00005)$. During the second $60 \mathrm{~s}$, the PIP at LC versus NC was $38 \pm 4.7$ versus $35.4 \pm 6.9 \mathrm{~cm} \mathrm{H}_{2} \mathrm{O}(\mathrm{p}=0.052)$. The TV generated at $\mathrm{LC}$ versus $\mathrm{NC}$ was $4.0 \pm 2.1$ versus $13.1 \pm 5.0 \mathrm{~mL}$ $\mathrm{cm} \mathrm{H}_{2} \mathrm{O}(\mathrm{p}=0.00005)$. (table 1$)$

\section{FMV/CC (paired analysis)}

At LC versus NC, the PIP was higher during the first $60 \mathrm{~s}$, that is, $1.7 \pm 2.2 \mathrm{~cm} \mathrm{H}_{2} \mathrm{O} \quad(\mathrm{p}=0.0003)$, but comparable during the

Table 2 Paired analysis of positive inflating pressure (PIP) and tidal volume in subjects at low and normal compliance during the first and second $60 \mathrm{~s}$ of combined chest compressions and FMV, and during FMV only

\begin{tabular}{llc}
\hline CPR/FMV & $\begin{array}{l}\text { Positive inflating } \\
\text { pressure }\left(\mathrm{cm} \mathrm{H}_{2} \mathrm{O}\right)\end{array}$ & $\begin{array}{l}\text { Tidal volume } \\
\left(\mathrm{mL} / \mathrm{cm} \mathrm{H}_{2} \mathrm{O}\right)\end{array}$ \\
\hline $\begin{array}{l}\text { Low vs normal compliance } \\
\text { (first } 60 \mathrm{~s})\end{array}$ & $1.7 \pm 2.2^{*}$ & $-10.8 \pm 6.5^{* *}$ \\
$\begin{array}{l}\text { Low vs normal compliance } \\
\text { (second } 60 \mathrm{~s})\end{array}$ & $0(\mathrm{IQ} 3)$ & $-9 \pm 4.8^{* *}$ \\
$\begin{array}{l}\text { FMV only } \\
\text { Low vs normal compliance }\end{array}$ & $7 \pm 5.8^{* *}$ & $-12.5 \pm 3.6^{* *}$ \\
\hline${ }^{*} \mathrm{p}=0.0003,{ }^{* *} \mathrm{p}=0.00005$. \\
CPR, chest compressions; FMV, face mask ventilation.
\end{tabular}



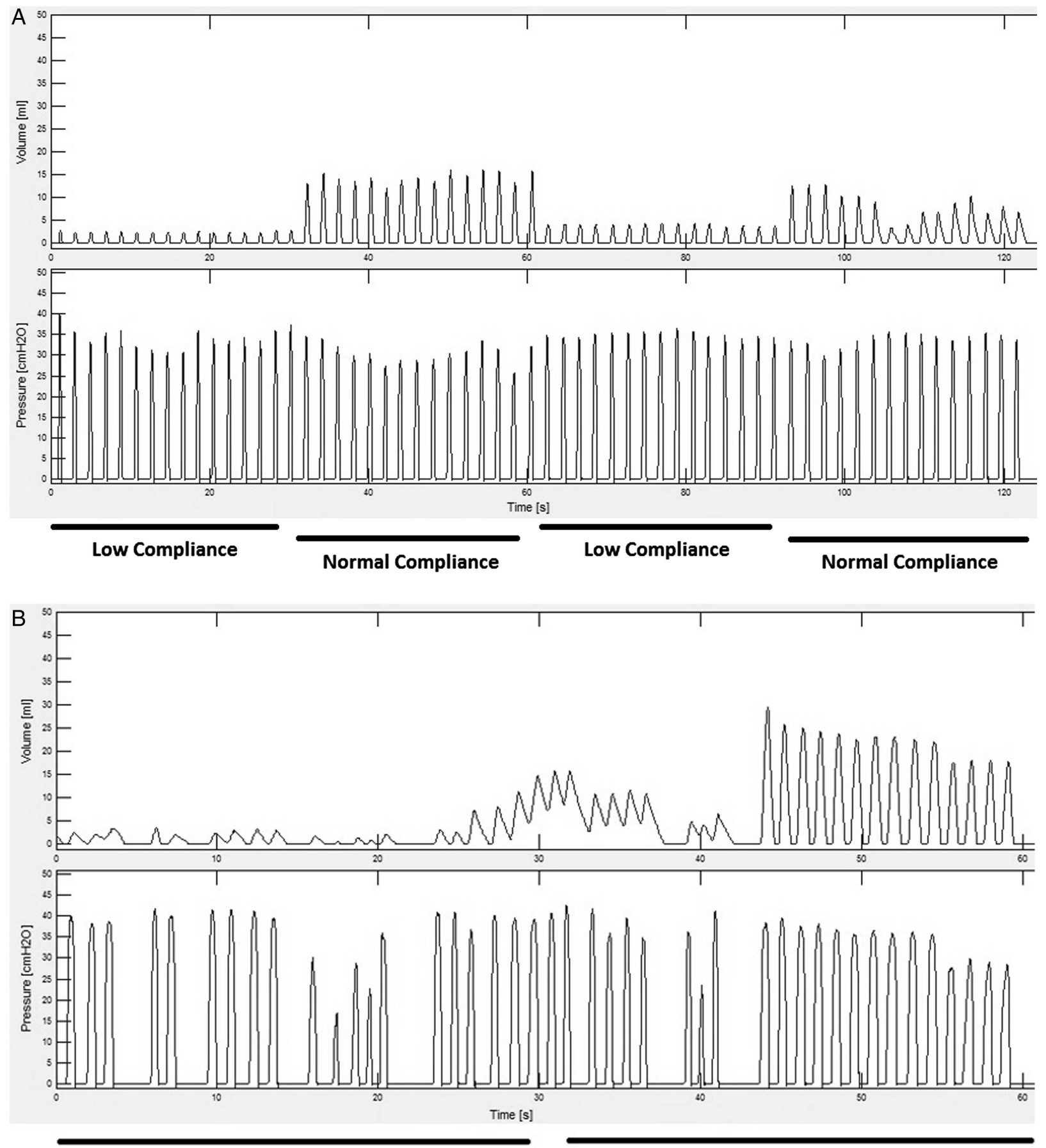

Low Compliance

Normal Compliance

Figure 1 (A) Positive inflating pressure (PIP) (bottom panel) and tidal volume (TV) (top panel) tracing from a provider during low compliance (initial $30 \mathrm{~s}$ ), normal compliance (second $30 \mathrm{~s}$ ), low compliance (30 s) and normal compliance (30 s) during synchronised chest compressions. Note minimal change in PIP during the two minutes, but a significant increase in TV with normal compliance. (B) PIP (bottom panel) and tidal volume (top panel) tracing from the same provider during low compliance (initial $30 \mathrm{~s}$ ), normal compliance (second $30 \mathrm{~s}$ ) during face mask ventilation only. Note attempts to augment ventilation and a reduction in PIP when compliance improved.

second $60 \mathrm{~s}$, that is, 0 (median, IQR 3) $(\mathrm{p}=0.49)$. At LC versus NC, the TV generated was less at both time points, that is, -10.8 \pm 6.5 and $-9 \pm 4.8 \mathrm{~mL} \mathrm{cmH}_{2} \mathrm{O}(\mathrm{p}=0.00005)$ (paired analysis, table 2).

FMV only (group analysis)

During the initial $30 \mathrm{~s}$, the PIP at LC versus NC was $40.5 \pm 5.0$ versus $33.4 \pm 8.5 \mathrm{~cm} \mathrm{H}_{2} \mathrm{O}(\mathrm{p}=0.00005)$. The TV generated at LC versus $\mathrm{NC}$ was $3.7 \pm 1.27 \mathrm{cmH}_{2} \mathrm{O}$ versus $16.2 \pm 3.56 \mathrm{~mL} / \mathrm{cm} \mathrm{H}_{2} \mathrm{O}$ $(\mathrm{p}=0.00005)$.

\section{FMV only}

At LC versus $\mathrm{NC}$ the PIP was higher, that is, $7 \pm 5.8 \mathrm{~cm} \mathrm{H}_{2} \mathrm{O}$ $(p=0.00005)$ and the TV lower, that is, $-12.5 \pm 3.6 \mathrm{~mL} / \mathrm{cm} \mathrm{H}_{2} \mathrm{O}$ $(p=0.00005)$ (paired analysis). 


\section{Descriptive analysis}

During combined CC and FMV, the face mask was incorrectly applied in $12 / 30(40 \%)$ of the studies without any attempt to reposition the mask. In 20/30 (67\%) cases, the provider did not perceive a change in compliance during the 2 min (figure 1A). During FMV, only 7/30 (23\%) took corrective steps as outlined by MR SOPA in order to achieve chest rise (figure 1B).

\section{DISCUSSION}

The findings in this manikin study indicate that when CC are administered while FMV is applied in a 3:1 ratio, the majority of providers $(67 \%)$ cannot perceive whether the delivery of TV is effective in the face of changing compliance, and failed to take corrective actions at LC. Moreover, as compliance improved, providers failed to lower the inflating pressure resulting in a tripling of the TV delivered. However, when FMV was applied without CC, some providers (20\%) took corrective action to achieve chest wall excursion with LC, and most lowered the inflation pressure as compliance improved. Additionally, consistent with prior reports, providers incorrectly applied the face mask in a substantial number of cases with and without CC. $^{12} 13$

Administration of CPR in the delivery room is uncommon. ${ }^{12}$ Much of the focus in the past has been on optimising effective CC. Thus, it has been previously shown in manikin models, that use of the two-thumb technique and a 3:1 CC to ventilation (CV) ratio enhances the ergonomics of $\mathrm{CC}^{4-7}$ More recently, the focus has shifted to provider ability to deliver effective ventilation during CC. Schmölzer et al used a neonatal manikin, reported substantial mask leak during $\mathrm{CC} .{ }^{8}$ In a second study, Solevag et al noted compromised TV with higher CV ratios was used as compared with a $3: 1$ ratio. ${ }^{9}$ Although we did not measure leak, approximately $40 \%$ of the provider did not apply the mask appropriately. Given these multiple potential problems with FMV, if the heart rate remains low, early consideration for intubation should be given even before initiation of CPR, in order to optimise ventilation.

There are several limitations to this study. First, we used a manikin model in which chest stiffness, resistance or change in compliance may not accurately represent similar characteristics in the same-sized human. Second, the sample size was relatively small. However, the almost uniform failure to identify the change in compliance during CC makes this less of an issue. Finally, there was a lack of objective outcome measures, such as change in heart rate in response to the applied inflating pressure, although with synchronised CPR, providers may not readily perceive difficulties with ventilation in the face of persistent bradycardia.

In conclusion, when administering synchronised CC, providers should focus on delivering effective ventilation. This may be difficult to discern due to numerous factors including LC, improper face mask application and leak, which limits the ability to make appropriate and necessary adjustments. This may prolong CPR, and may result in escalating therapies unrelated to the delivery of effective ventilation. These findings strongly suggest that when CCs are stopped intermittently to evaluate heart rate, a concomitant quick assessment for optimal face mask application and chest rise should be undertaken to ensure effective ventilation prior to resuming CC, particularly with a persistent low heart rate. In the face of a persistent heart rate $<60 \mathrm{bpm}$, or asystole, early intubation should be considered as the next intervention to enhance effective ventilation.

Contributors TH helped in the design of the study, in the collection and overseeing of the data and was involved in the writing of the manuscript and approved the final version of the manuscript. RJH RNC helped in the design of the study, in the collection and was involved in the writing of the manuscript and approved the final version of the manuscript. JMP conceptualised and designed the study, contributed to design of the analyses and interpretation of the results, took the lead in drafting the initial and subsequent versions of the manuscript and ensured that all authors approved the final version of the manuscript.

Funding The neonatal lung simulator was provided by the Laerdal Corporation. Competing interests None.

Ethics approval Institutional Review Board at Weill Conell Medical College. Provenance and peer review Not commissioned; externally peer reviewed.

\section{REFERENCES}

1 Perlman JM, Risser R. Cardiopulmonary resuscitation in the delivery room. Associated clinical events. Arch Pediatr Adolesc Med 1995;149:20-5.

2 Barber CA, Wyckoff MH. Use and efficacy of endotracheal versus intravenous epinephrine during neonatal cardiopulmonary resuscitation in the delivery room. Pediatrics 2006;118:1028-34.

3 Perlman JM, Wyllie J, Kattwinkel J, et al. Part 11: neonatal resuscitation: 2010 International Consensus on Cardiopulmonary Resuscitation and Emergency Cardiovascular Care Science with Treatment Recommendations. Circulation 2010;122:516-38.

4 Christman C, Hemway RJ, Wyckoff MW, et al. The two thumb is superior to the two finger method for administering chest compressions in newly born infants. Arch Dis Child Fetal Neonatal Ed 2011;96:F99-101.

5 Hemway RJ, Christman C, Perlman JM. The 3:1 is superior to a 15:2 ratio in a newborn manikin model in terms of quality of chest compressions and number of ventilations. Arch Dis Childhood 2013;98:F42-5.

6 Houri PK, Frank LR, Menegazzi JJ, et al. A randomized, controlled trial of two-thumb vs two-finger chest compression in a swine infant model of cardiac arrest [see comment]. Prehosp Emerg Care 1997;1:65-7.

7 Wyckoff MH, Berg RA. Optimizing chest compressions during delivery-room resuscitation. Semin Fetal Neonatal Med 2008;13:410-15.

8 Schmölzer G, Roehr C, Wong C. Which musical tune improves synchronization of respiratory support during simulated cardio-pulmonary resuscitation of neonates? Arch Dis Child 2012;97:A510-11.

9 Solevåg AL, Madland JM, Gjærum E, et al. Minute ventilation at different compression to ventilation ratios, different ventilation rates, and continuous chest compressions with asynchronous ventilation in a newborn manikin. Scand I Trauma Resusc Emerg Med 2012;20:73.

10 Finer NN, Rich W, Wang C, et al. Airway obstruction during mask ventilation of very low birth weight infants during neonatal resuscitation. Pediatrics 2009;123:865-9.

11 Poulton DA, Schmölzer GM, Morley CJ, et al. Assessment of chest rise during mask ventilation of preterm infants in the delivery room. Resuscitation 2011;82:175-9.

12 Wood FE, Morley CJ, Dawson JA, et al. Improved techniques reduce face mask leak during simulated neonatal resuscitation: study 2. Arch Dis Child Fetal Neonatal Ed 2008;93:F230-4.

13 Tracy MB, Klimek J, Coughtrey $\mathrm{H}$, et al. Mask leak in one person mask ventilation compared to two-person in newborn infant manikin study. Arch Dis Child Fetal Neonatal Ed 2010;96:F195-200. 